\title{
Recurrent Miscarriage in the Context of COVID-19 Pandemic: Is There An Association?
}

\author{
Omnia El-Badawy ${ }^{1}$, Asmaa S Shaltout ${ }^{1}$ and Ahmed M Abbas ${ }^{2 *}$ \\ ${ }^{1}$ Department of Medical Microbiology \& Immunology, Faculty of Medicine, Assiut University, Egypt \\ ${ }^{2}$ Department of Obstetrics \& Gynecology, Faculty of Medicine, Assiut University, Assiut, Egypt
}

\begin{abstract}
Corona virus disease 2019 (COVID-19) is considered a worldwide pandemic. COVID-19 patients had profound immune dysregulation, so they could be susceptible for adverse pregnancy outcomes as preeclampsia and miscarriage. In this mini-review, we tried to explain the link between recurrent miscarriage and COVID-19.
\end{abstract}

The ongoing corona virus disease-2019 (COVID-19) is a global public health emergency. Little is known about the effect of COVID-19 on pregnancy [1]. Data are mostly limited to small case series and controversies exist about its impact on pregnancy outcomes. A multicenter study included 116 pregnant women with COVID-19 from 25 hospitals in China reported that infection during pregnancy is not associated with an increased risk of spontaneous miscarriage or preterm birth (PTB) [2]. Additionally, they reported no evidence of vertical transmission of infection during pregnancy [2]. On the contrary, in a meta-analysis combining data from pooled proportions in 19 studies, > 90\% of them also had pneumonia, PTB was the most frequent adverse pregnancy outcome. Miscarriage, cesarean sections, preeclampsia and perinatal death (7-11\%) were also higher than in the general population, with no evidence of vertical transmission of the virus [1].

It is well established that pregnant women are more harshly affected by some viral infections [3]. Since the COVID-19 is most probably not transmitted to the growing embryo, and our aim in this review is to find an explanation of the possible cause of this potential risk. The immunological influences play a pivotal role in embryonic development, and implantation [4]. Endometrial receptiveness is linked to multiple immunological factors including cytokines [5].

Several studies agreed that COVID-19 patients had profound immune dysregulation including marked reduction in the level of lymphocytes, especially natural killer (NK) cells, which is clearly manifest in severe cases [6-10]. Both uterine NK cells and regulatory-T cells (Tregs) have been shown to be potent sources of anti-inflammatory molecules that play a key role in the maintenance of pregnancy [11]. NK cells are critical for the development of the placenta and prevent semi-Allogeneic fetus rejection [12]. Patients with COVID-19 had lower levels of Tregs, and NK cells and even undetectable in severe cases, whether this reduction affects pregnancy or not needs further investigations [13].

In severe COVID-19, although patients have lymphocytopenia, the lymphocytes were activated [14]. The expression of CD8 on the cytolytic T lymphocytes, which is important for T-cell activity, raised significantly [15], and the cytotoxic particles as perforin and granulysin were greatly expressed in CD8+ $T$ cells [16]. T lymphocytes may be trying to raise their cytotoxic activity [17]. Disturbances in NK cells are largely implicated in recurrent spontaneous miscarriages (RSM) [18], could the cytotoxic activity by these cells be up regulated as well to the level causing poor pregnancy outcomes is a matter that necessitates future studying.

A common feature in COVID-19 patients is having extremely high inflammatory parameters, including high levels of cytokines resembling cytokine storm (CS) in SARS and MERS (including IL-6, TNF $\alpha$, IL-8, IL-2, IL-7, IL-8, IL-9, IL-10, G-CSF, IP10, MCP1, MIP1A, IFN $ү$...etc.) $[7,9,19]$. In one study [9], in most of the severe COVID-19 patients, this CS was associated with hypercoagulability and disseminated intravascular coagulopathy (DIC). Local and systemic inflammatory processes exaggerate the cascade of inflammatory cytokine production with coagulation and ischemia that may lead to adverse pregnancy outcomes including implantation failure,

*Corresponding author: Ahmed M Abbas, MD, Department of Obstetrics and Gynecology, Faculty of Medicine, Assiut University, Women Health Hospital, 71511, Assiut, Egypt, Tel: +20-882414616, Fax: +20-88-9202503

Accepted: September 26, 2020

Published online: September 28, 2020

Citation: El-Badawy O, Shaltout AS, Abbas AM (2020) Recurrent Miscarriage in the Context of COVID-19 Pandemic: Is There An Association?. Annals Gynecol Obstet 4(1):77-78 
pregnancy loss, PTB, fetal inflammatory syndrome, and even RSM $[20,21]$. These assumptions need further studies to validate them in the future.

In conclusion, we still have limited knowledge about the effect of COVID-19 on early pregnancy. Further studies are recommended to show the association between COVID-19 and RSM. Until further research is available, we suggest that obstetricians should be aware of the risk of RSM among pregnant women contagious to a positive COVID-19 patient or had a history of suggestive symptoms in early pregnancy.

\section{Conflict of Interest}

The authors state that there are no conflicts of interest.

\section{References}

1. Di Mascio D, Khalil A, Saccone G, et al. (2020) Outcome of corona virus spectrum infections (SARS, MERS, COVID 1 -19) during pregnancy: A systematic review and meta-analysis. American Journal Of Obstetrics \& Gynecology MFM 100107.

2. Zhang J, Xie B, Hashimoto K (2020) Current status of potential therapeutic candidates for the COVID-19 crisis. Brain Behav Immun 87: 59-73.

3. Kourtis AP, Read JS, Jamieson DJ (2014) Pregnancy and infection. The New England Journal of Medicine. 370: 2211-2218.

4. Kwak-Kim J, Park JC, Ahn HK, et al. (2010) Immunological modes of pregnancy loss. Am J Reprod Immunol 63: 611-623.

5. Wilcox AJ, Weinberg CR, O'Connor JF, et al. (1988) Incidence of early loss of pregnancy. N Engl J Med 319: 189-194.

6. Diao B, Wang C, Tan Y, et al. (2019) Reduction and functional exhaustion of T Cells in patients with corona virus disease 2019 (COVID-19). Front Immunol 11: 827.

7. Huang C, Wang Y, Li X, et al. (2020) Clinical features of patients infected with 2019 novel corona virus in Wuhan, China. Lancet 395: 497-506.

8. Wang D, Hu B, Hu C, et al. (2020) Clinical characteristics of 138 hospitalized patients with 2019 novel corona virus-infected pneumonia in Wuhan, China. Jama 323: 1061-1069.

9. Zhang W, Zhao Y, Zhang F, et al. (2020) The use of anti-inflammatory drugs in the treatment of people with severe corona virus disease 2019 (COVID-19): The perspectives of clinical immunologists from China. Clin Immunol 214: 108393.

10. He R, Lu Z, Zhang L, et al. (2020) The clinical course and its correlated immune status in COVID-19 pneumonia. J Clin Virol 127: 104361.

11. Sharma S (2014) Natural killer cells and regulatory T Cells in early pregnancy loss. Int J Dev Biol 58: 219-229.

12. Moffett-King A (2002) Natural killer cells and pregnancy. Nat Rev Immunol 2: 656-663.

13. Qin C, Zhou L, Hu Z, et al. (2020) Dysregulation of immune response in patients with COVID-19 in Wuhan, China. Clin Infect Dis.

14. Wan S, Yi Q, Fan S, et al. (2020) Characteristics of lymphocyte subsets and cytokines in peripheral blood of 123 hospitalized patients with 2019 novel corona virus pneumonia (NCP). MedRxiv.

15. Ganji A, Farahani I, Khansarinejad B, et al. (2020) Increased expression of CD8 marker on T-cells in COVID-19 patients. Blood Cells Mol Dis 83: 102437.

16. Xu Z, Shi L, Wang Y, et al. (2020) Pathological findings of COVID-19 associated with acute respiratory distress syndrome. Lancet Respir Med 8: 420-422.

17. Sun $P$, Lu X, Xu C, et al. (2020) Understanding of COVID-19 based on current evidence. J Med Virol 92: 548-551.

18. El-Badawy O, Helmy AS, Abbas AM, et al. (2020) Concordance between peripheral and decidual NK cell subsets and killer immunoglobulin-like receptors in women with recurrent spontaneous miscarriages. Journal of Reproductive Immunology 140: 103130.

19. Conti P, Ronconi G, Caraffa A, et al. (2020) Induction of pro-inflammatory cytokines (IL-1 and IL-6) and lung inflammation by Coronavirus-19 (COVI-19 or SARS-CoV-2): Anti-inflammatory strategies. J Biol Regul Homeost Agents 34: 327-331.

20. Kwak-Kim J, Yang KM, Gilman-Sachs A (2009) Recurrent pregnancy loss: A disease of inflammation and coagulation. J Obstet Gynaecol Res 35: 609-622.

21. Kwak-Kim JY, Chung-Bang HS, Ng SC, et al. (2003) Increased T helper 1 cytokine responses by circulating $T$ cells are present in women with recurrent pregnancy losses and in infertile women with multiple implantation failures after IVF. Human Reproduction 18: 767-773.

DOI: $10.36959 / 468 / 470$

Copyright: (C) 2020 El-Badawy O, et al. This is an open-access article distributed under the terms of the Creative Commons Attribution License, which permits unrestricted use, distribution, and reproduction in any medium, provided the original author and source are credited. 